\title{
Idiopathic pyoderma gangrenosum
}

\section{Amina Lamouaffaq, Salim Gallouj, Hanane Baybay, Fatima Zahra Mernissi}

\author{
Department of Dermatology, University Hospital Hassan II Fez, Morocco
}

Corresponding author: Dr. Amina Lamouaffaq, E-mail: a.lamouaffaq@gmail.com

Sir,

A 36-year-old patient with no pathological pathology who presented 6 months before admission pustular lesions increasing in size and number and becoming ulcerated in the legs of centrifugal evolution, painful, without other associated signs including rheumatological digestive or other (Figs. la $-1 \mathrm{~d}$ ).

Clinical examination revealed multiple ulcers, well limited, purplish, necrotic in center, of varying sizes, the edges was raised with pus. The lesions were in the legs and there were no extra cutaneous manifestations. Biological tests were normal and the histology was in favor of pyoderma gangrenosum. The Idiopathic one was suggested due to exclusion of other usual associations.

The patient was treated by oral corticotherapy with good evolution.

Pyoderma gangrenosum (PG) is a neutrophilic dermatosis with unclear etiology [1]. Described in 1930 by Brunstig et al [2]. It is a noninfectious disease characterized by necrotizing, ulcerative and painful skin, whose incidence is approximately 3-10 cases per million people per year and it is rarely observed in children, accounting for less than $4 \%$ of cases, but primarily affects adults between the ages of 25 and 54 years old without gender preference [3]. PG can associate with inflammatory, infectious or malignant pathologies or be idiopathic [4]. It presents initially with coalescent inflammatory pustules, which fuse progressively leaving reveal a necrotic ulcer, with hypertrophic edges well defined, of purplish color. The base of the ulcer is often under-mined, indicating early subcutaneous inflammatory extension, with secondary ulceration of the epidermis, the lesions predominate classically in the lower limbs or the trunk, but can be observed on the whole of the cutaneous surface. Exceptionally, il may spread to extracutaneous tissues, with pulmonary infiltrates or joint involvement simulating true septic arthritis.

PG remains at present a clinical diagnosis of exclusion. The histological aspect reveals most often nonspecific, but helps to exclude other potential causes [5].

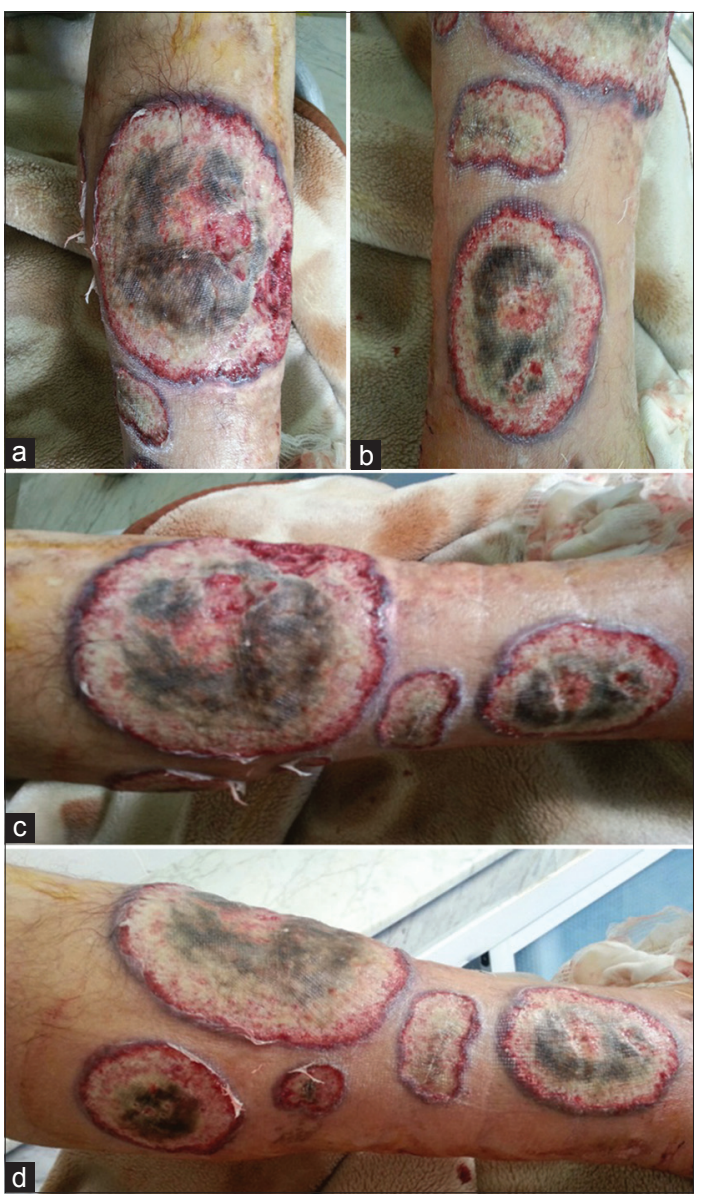

Figure 1: (a-d) Ulcerations well limited, with raised, erythematous - purplish and inflammatory margins.

\footnotetext{
How to cite this article: Lamouaffaq A, Gallouj S, Baybay H, Mernissi FZ. Idiopathic pyoderma gangrenosum. Our Dermatol Online. 2019;10(3):306-307. 
The evocative histology includes a dense and deep dermal infiltrate consisting of neutrophils without vasculitis, associated with a necrotic ulceration appearance, and the treatment remains poorly codified to date. It is mainly based on general or local corticosteroids, immunosuppressors and certain anti-inflammatory antibiotics [2].

\section{Consent}

The examination of the patient was conducted according to the Declaration of Helsinki principles.

\section{REFERENCES}

1. Afifi L, Sanchez IM, Wallace MM, Braswell SF, Ortega-Loayza AG, Shinkai K. Diagnosis and management of peristomal pyoderma gangrenosum: A systematic review. J Am Acad Dermatol. 2018;78:1195-204.

2. Anuset D, Reguiai Z, Perceau G, Colomb M, Durlach A, Bernard P. [Clinical patterns and treatment of pyoderma gangrenosum in a French department]. Ann Dermatol Venereol. 2016;143:108-17.

3. Al Dossary SJ, Tariq S. AlFawaz, Awatif K. AlMutairi. Pyoderma gangrenosum with splenic involvement. Int J Ped Adoles Med. 2016;3:78-80.

4. Rabhi F, Zaouak A, Koubaa W, Hammami H, Fenniche S. Pyoderma Gangrénosum: à propos de 14 cas. Rev Méd Intern. 2017;38S: A109-A248.

5. P.-N. Carron S.Yerly R. Ksontini P. Meylan T. Calandra. Pyoderma gangrenosum: diagnostic and therapeutic challenge. Rev Med Suisse. 2008;4:1938-43.

Copyright by Amina Lamouaffaq, et al. This is an open access article distributed under the terms of the Creative Commons Attribution License, which permits unrestricted use, distribution, and reproduction in any medium, provided the original author and source are credited.

Source of Support: Nil, Conflict of Interest: None declared. 